\title{
Gold Vinylidenes as Useful Intermediates in Synthetic Organic Chemistry
}

\author{
Fabien Gagosz* (D) \\ Department of Chemistry and Biomolecular Sciences, University of \\ Ottawa, K1N 6N5, Ottawa, Canada \\ fgagosz@uottawa.ca \\ Published as part of the 50 Years SYNTHESIS - Golden Anniversary Issue
}

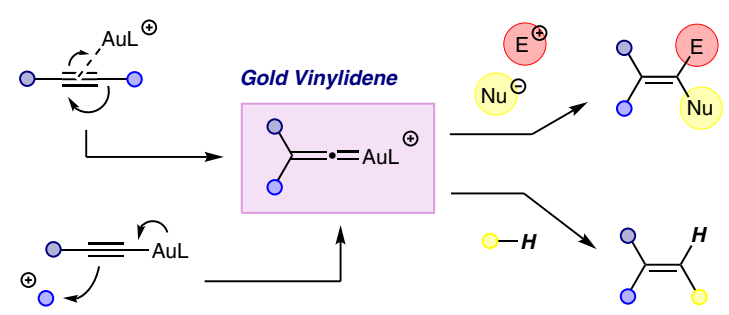

Received: 02.12.2018

Accepted: 05.12.2018

Published online: 10.01 .2019

DOI: 10.1055/s-0037-1611647; Art ID: ss-2018-z0809-sr

License terms: CCO

Abstract Gold vinylidenes have recently emerged as useful intermediates in synthetic organic chemistry. These species, which can principally be accessed by a 1,2-migration process from a gold-activated alkyne or by dual gold catalysis on a diyne substrate, can react with nucleophilic partners or by $\mathrm{C}-\mathrm{H}$ insertion to produce a variety of functionalized (poly)cyclic compounds. This short review covers the synthetic approaches developed so far to access gold vinylidenes and the different reactivities these species can exhibit.

Introduction

1,2-Migration Processes

Dual Gold Catalysis

Other Processes

Conclusion

Key words vinylidene, reactive intermediate, gold, catalysis, dual catalysis, nucleophilic trapping, $\mathrm{C}-\mathrm{H}$ insertion

\section{Introduction}

Since its emergence more than 15 years ago, homogeneous gold catalysis has developed into a very active area of research. ${ }^{1}$ The straightforward access to various gold complexes, their ease of use and general high stability, allied to the variety of selective and unusual transformations they can allow, have enabled homogenous gold catalysis to become a synthetic tool of choice for the generation of molecular diversity and structural complexity. Since gold catalysts are electrophilic in nature and particularly prone to activate carbon-carbon systems, a large number of the synthetic transformations reported to date involve cationic in- termediates, whose reactivity can be modulated, to some extent, by the presence of the gold moiety. Gold carbenes of type $\mathbf{1}$, for instance, have been intensively studied (Scheme 1). ${ }^{1,2}$ They can be accessed from a variety of substrates, under different reaction conditions and following a range of mechanistic pathways. In sharp contrast, and while their first appearance in the literature as potential intermediates in a synthetic transformation dated from 2004, gold vinylidenes species $\mathbf{2}$ have comparatively attracted less attention. ${ }^{3}$ Such a situation can probably be imputed to a longstanding lack of synthetic processes to access them in an easy and selective manner. 


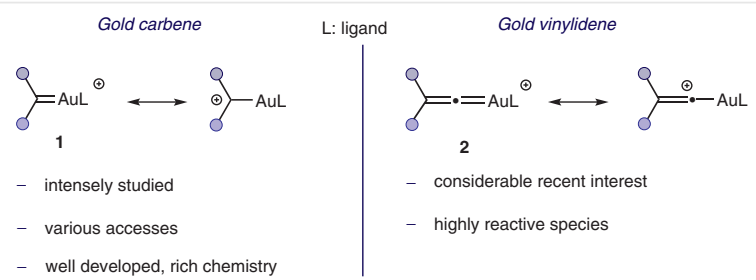

Scheme 1 Gold carbene and gold vinylidene species

The context changed in 2012 when the groups of Hashmi and Zhang discovered that arenediyne substrates could be used for the generation of gold vinylidenes, and that these species demonstrated interesting reactivities. Since then, more attention has been focused onto the field and a variety of synthetic transformations based on their involvement as key reactive species have been reported.

The aim of this short review is to give the reader an overview of the synthetic approaches developed so far to access gold vinylidenes and the various reactivities these species can exhibit. It is organized by means of gold vinylidene generation: 1) 1,2-migration processes, 2) dual gold catalysis, and 3) other unrelated processes. The reactivities of gold vinylidenes are illustrated for each transformation by a short selection of representative examples.

\section{1,2-Migration Processes}

The treatment of an alkyne substrate $\mathbf{3}$ bearing either a halogen atom $(\mathrm{Br}, \mathrm{I})$ or a trialkylsilyl $\left(\mathrm{SiR}_{3}\right)$ substituent with an electrophilic gold species is probably the most straightforward manner to generate vinylidene gold species (Scheme 2). Indeed, upon activation of the $\mathrm{C} \equiv \mathrm{C}$ bond by gold, the $\mathrm{X}$ group can perform a 1,2-migration to deliver a vinylidene gold intermediate $\mathbf{4}$ that can then react via nucleophilic trapping or $\mathrm{C}-\mathrm{H}$ bond insertion.

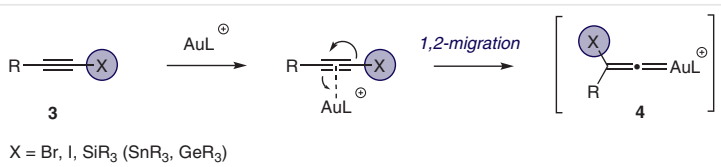

Scheme 2 Generation of gold vinylidene species from alkynes by 1,2migratory process

The very first example of such a reactivity (and involvement of a vinylidene gold species in a synthetic process) was reported by Fürstner and co-workers in 2004. ${ }^{4}$ While working on the synthesis of substituted phenanthrene by cycloisomerization of 0 -alkynylbiaryl derivatives, they observed that bromo- and iodoalkynes $\mathbf{5}_{\mathrm{Br}}$ and $\mathbf{5}_{\mathrm{I}}$ were rearranged selectively into phenanthrene $\mathbf{6}_{\mathrm{Br}}$ and $\mathbf{6}_{\mathrm{I}}$ in the presence of $\mathrm{AuCl}$ (Scheme 3). This reactivity was attributed to the involvement of a vinylidene gold species $\mathbf{7}$ that cyclizes onto the pendant aryl motif. DFT studies performed by So- riano and Marco-Contelles brought support to the proposed mechanism. ${ }^{5}$ Interestingly, the use of $\mathrm{InCl}_{3}$ as the catalyst led to a divergent reactivity with the selective formation of the regioisomeric 10-halophenanthrenes 8.
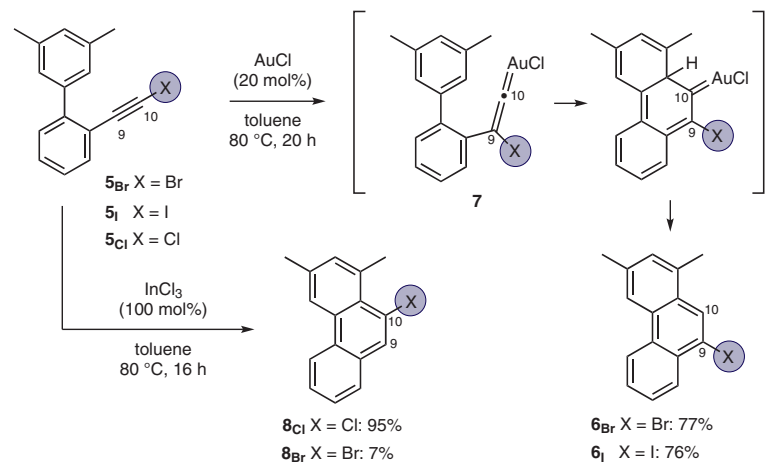

Scheme 3 Synthesis of halophenanthrenes from haloalkynes

The same concept of 1,2-halogen migration was exploited by the group of González for the formation of dehydroiodoquinolines from iodopropargyl amide derivatives $\mathbf{9}$ (Scheme 4). ${ }^{6}$ The authors found that the selectivity was dependent on the nature of the gold(I) complex employed. The use of [(IPr)Au]NTf ${ }_{2}(\mathbf{1 3})$ as the catalyst favored the iodine migration product 11, while a phosphite-based gold complex 14 led majorly to the product of direct cyclization 12. This divergence in selectivity was explained by considering the difference of electrophilicity between the two catalysts and the ability of NHC-based gold complexes to more favorably stabilize the vinylidene gold intermediate 10. ${ }^{7}$ The reaction was shown to be particularly selective in the case of substrates possessing electron-withdrawing aryl substituents, as the competitive direct cyclization was slowed down in such cases. The same authors also reported that the 1,2-iodine migration process could also be employed for the selective synthesis of 3-iodo- $2 \mathrm{H}$-chromenes (Scheme 4). ${ }^{8}$

More recently, González and co-workers demonstrated that aryliodoalkynes $\mathbf{1 5}$ could also be employed as substrates for the synthesis of functionalized indenes $17 .{ }^{9}$ In this case, the intermediate gold iodovinylidene species $\mathbf{1 6}$ cyclizes following a concerted $\mathrm{C}-\mathrm{H}$ bond insertion at the benzylic position of the substrate (Scheme 5). This procedure represents a particularly efficient entry to iodoindenes.

The group of Hashmi also proposed the involvement of similar gold iodovinylidene intermediates in a synthesis of 1,3-diodonaphthalenes $\mathbf{2 0}$ from 1,2-bis(iodoethyl)arenes $\mathbf{1 8}$ (Scheme 6). ${ }^{10}$ In this transformation, the electrophilic species 19 was proposed to cyclize onto the pendant iodoalkyne thus inducing the nucleophilic addition of benzene. This process could also be applied to enediyne or bromoalkyne derivatives. 
Besides halogen atoms, it was also reported that silyl groups could undergo 1,2-migration upon activation of a silylalkyne with an electrophilic gold species. However, ex-

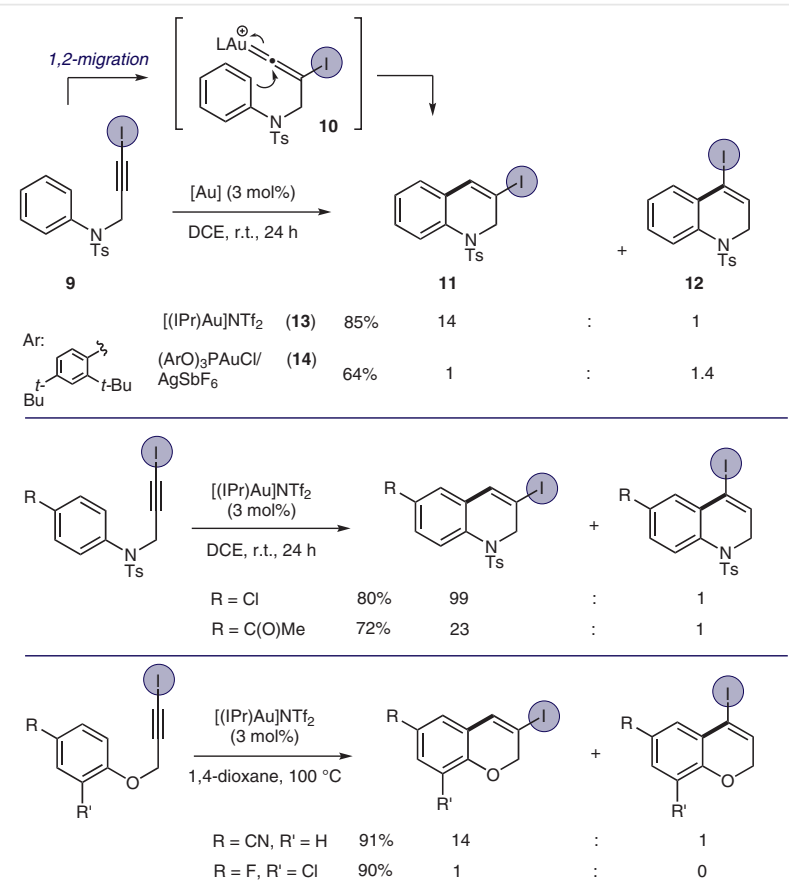

Scheme 4 Synthesis of 3-iododehydroquinolines and -2H-chromenes
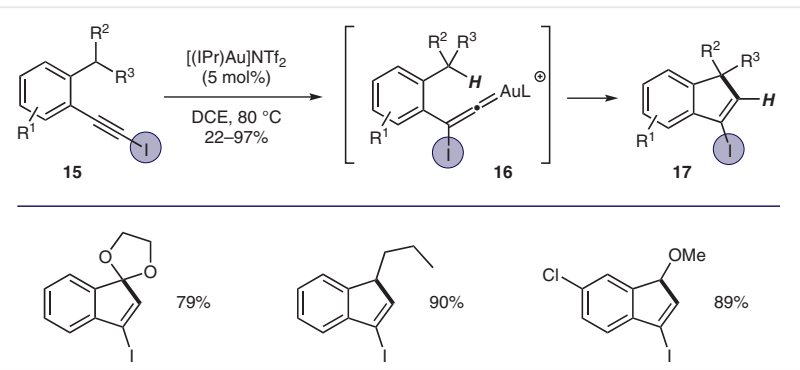

Scheme 5 Synthesis of 2-iodoindenes via gold iodovinylidene intermediates amples of such a reactivity remain rare. Seregin and Gevorgyan reported in 2006 that 2-propargylpyridine $\mathbf{2 1}$ could be rearranged into indolizine $\mathbf{2 3}$ when treated with $\mathrm{AuBr}_{3}$ in toluene at $50{ }^{\circ} \mathrm{C}$ (Scheme 7)..$^{11}$ This process was shown to be applicable to a series of other heterocyclic motifs. A mechanism involving the nucleophilic addition of the pyridine nitrogen atom onto an intermediate gold vinylidene $\mathbf{2 2}$ was initially proposed to explain the formation of 23 . DFT calculations conducted later on by Li and Gevorgyan led to question the likelihood of such a mechanism while not ruling it out, though. ${ }^{12}$

A more recent and unambiguous example of 1,2-silyl group migration was reported by the group of Barriault. ${ }^{13}$ During their studies on the total syntheses of biologically active polyprenylated polycyclic acylphloroglucinols, ${ }^{14}$ the authors isolated an intriguing organogold complex $\mathbf{2 5}$ that was produced when ynone $\mathbf{2 4}$ was reacted with a catalytic amount of [(JohnPhos)Au(NCMe)] $\mathrm{SbF}_{6}$ (Scheme 8). Intrigued by the structure of $\mathbf{2 5}$ and the relative position of the TBS group/the gold residue, the authors made a series of experiments which showed that: a) the process could be applied to other trialkylsilyl groups and b) alkenyl gold species of type $\mathbf{2 8}$ could be generated and isolated in the presence of various gold complexes. To explain this reactivity, a mechanism involving a gold vinylidene species $\mathbf{2 7}$, intermediately produced by 1,2-migration of the silyl group on the gold-activated $C \equiv C$, was proposed. Interestingly, the use of di- and triphenylsilyl groups prevents the migration thus
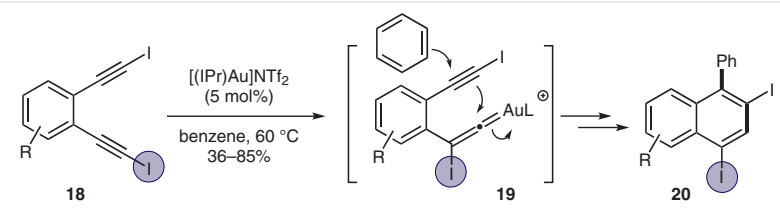<smiles>COc1cc2c(C)cc(I)c(-c3ccccc3)c2cc1OC</smiles><smiles>Cc1cc(I)c(-c2ccccc2)c2ccccc12</smiles><smiles>Cc1cc2c(Br)cc(Br)c(Br)c2cc1C</smiles>

Scheme 6 Synthesis of 1,3-diiodonaphthalenes

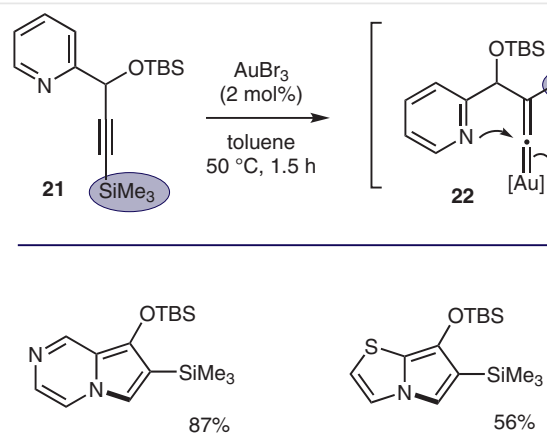
$5 \%$

Scheme 7 Postulated gold-mediated 1,2-silyl migration in the formation of fused pyrrole-containing heterocycles 
leading to the formation of the regioisomeric organogold complex. The authors also demonstrated that $\mathbf{2 8}$ could be efficiently demetalated in the presence of electrophilic species thus allowing the formation of further functionalized compound 29.

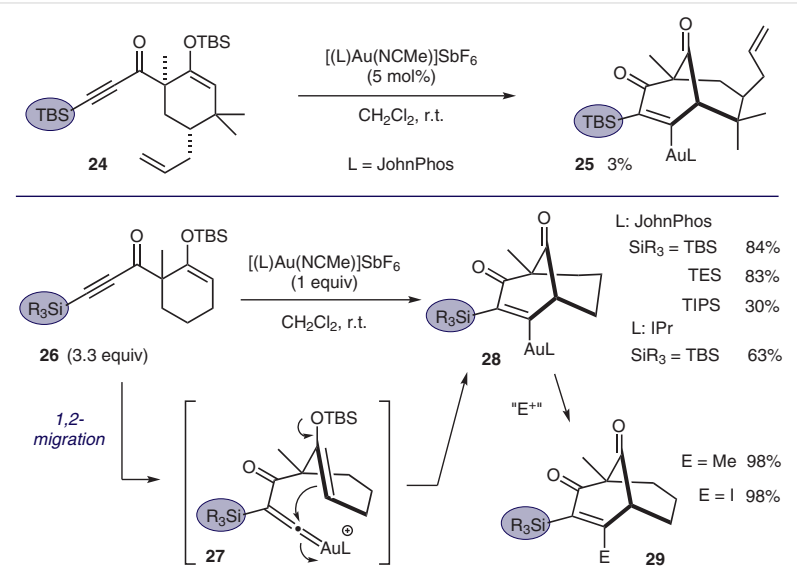

Scheme 8 Isolation of organogold complexes through 1,2-silyl group migration

While gold vinylidene species can be conveniently accessed by 1,2-migration from iodo- or silylalkynes, and subsequently involved in synthetically useful transformations, examples of such a reactivity remain rare in the literature. The migration process generally competes with the direct nucleophilic functionalization or with the dehalogenation/desilylation of the gold-activated alkyne.

\section{Dual Gold Catalysis}

A major breakthrough in the field of gold vinylidene chemistry was made when the group of Hashmi found in $2012^{15}$ that these reactive species could be conveniently generated by an intramolecular reaction between a nucleophilic goldacetylide $\mathbf{3 0}$ and a gold-activated alkyne $\mathbf{3 1}$ (Scheme 9). This important discovery paved the way to the development of a variety of dual gold-catalyzed processes ${ }^{16}$ which are based on the key generation of intermediate gold vinylidene species $\mathbf{3 2}$ from diyne substrates. These reactions are detailed in the following paragraphs.

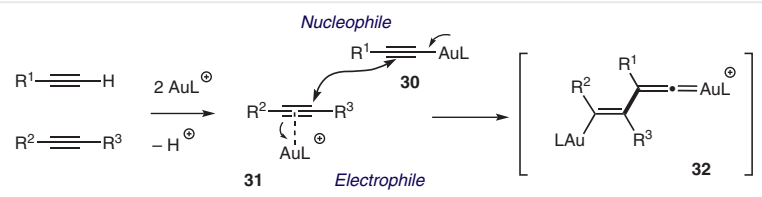

Scheme 9 Generation of gold vinylidene species from diyne by dual gold catalysis
The story started when Hashmi and co-workers studied the reaction of arenediyne $\mathbf{3 3}$ in the presence of the [(IPr)Au] $\mathrm{NTf}_{2}$ complex 13 in benzene (Scheme 10). When 33 was treated with $15 \mathrm{~mol} \%$ of $\mathbf{1 3}$ at $20^{\circ} \mathrm{C}$, benzene adduct 34 was produced almost as a single product. It was proposed that $\mathbf{3 4}$ was formed by an initial diyne cyclization followed by the trapping of the resulting naphthyl cation by a molecule of solvent. ${ }^{10,17}$ Surprisingly, when the reaction was conducted at reflux, another unexpected benzene adduct $\mathbf{3 5}$ was competitively formed. The authors discovered that the selectivity could even be completely shifted towards the formation of $\mathbf{3 5}$ in the presence of a basic additive $\left(\mathrm{Et}_{3} \mathrm{~N}\right)$. After an extensive and careful study of the influence of reaction conditions (nature of catalyst and loading, additive, temperature), as well as D-labeling experiments, the group of Hashmi proposed that the unexpected adduct 35 could be produced by an unusual mechanism involving the formation of an intermediate gold vinylidene species (Scheme 10). ${ }^{18}$

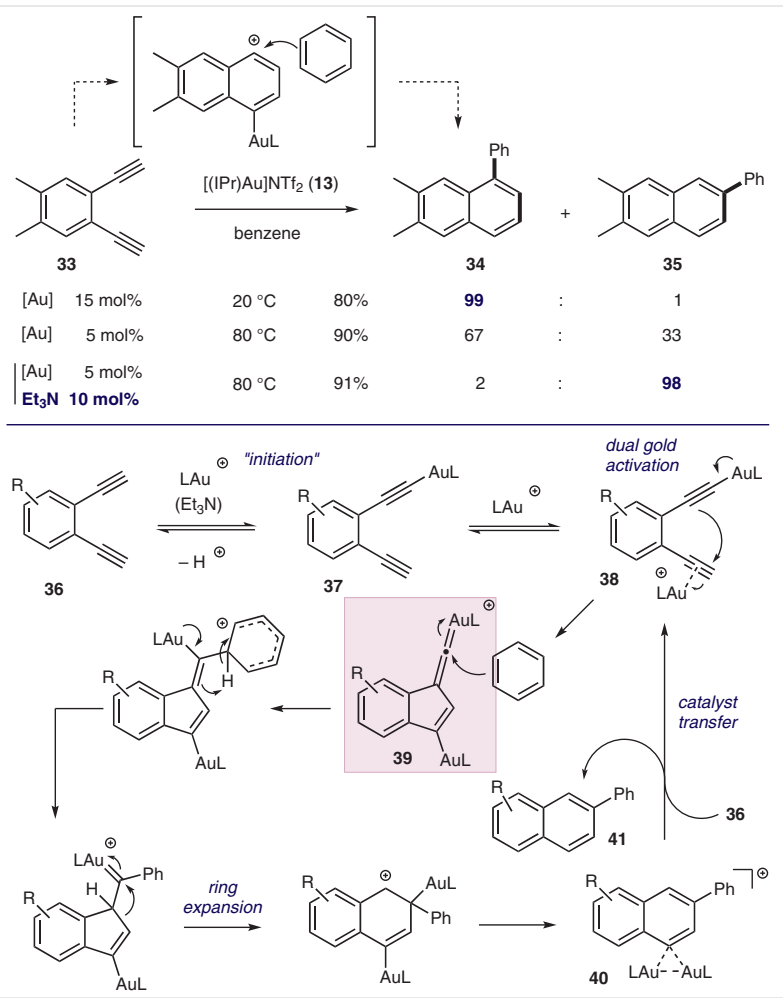

Scheme 10 Initial discovery by Hashmi and co-workers: gold vinylidene as an intermediate in the hydroarylating-aromatization of arenediynes

The transformation would be initiated by the formation of goldacetylide $\mathbf{3 7}$ from $\mathbf{3 6}$, a process that would be favored in the presence of $\mathrm{Et}_{3} \mathrm{~N}$ as an additive. A dual activation via 38 would then induce the formation of key gold vinylidene intermediate 39 , which would subsequently evolve into the gem-diaurated species $\mathbf{4 0}$ by a sequence of hydrogen trans- 
fer and ring expansion. The catalytic cycle would be closed by a catalyst transfer from $\mathbf{4 0}$ to $\mathbf{3 6}$ that would liberate the reaction product $\mathbf{4 1}$ and regenerate the di-gold complex 38 . It is worth noting that $\mathbf{4 0}$ could be isolated and was found to be catalytically active in the process.

By capitalizing on this result, and on the basis of their mechanistic investigations, the Hashmi group subsequently reported that dibenzopentalenes $\mathbf{4 3}$ could be synthesized by reacting diyne derivatives $\mathbf{4 2}$ in the presence of complex 13 (Scheme 11). ${ }^{19}$ In this transformation, the intermediate gold vinylidene $\mathbf{4 5}$, generated by dual gold catalysis, is trapped in an intermolecular manner by the pendant aryl group. Interestingly, no compounds derived from an intermolecular reaction of $\mathbf{4 5}$ with benzene (used as the solvent) was observed. The involvement of $\mathbf{4 5}$ in the process and the overall mechanistic proposal were supported by a series of computational studies. ${ }^{20}$ Of special interest is the catalyst transfer event, which was found to proceed between the gem-diaurated species $\mathbf{4 6}$ and $\mathbf{4 2}$ in a 3-step sequence comprising an initial $\mathrm{AuL}^{+}$transfer, followed by a proton transfer and a second $\mathrm{AuL}^{+}$transfer. ${ }^{20 \mathrm{~b}}$
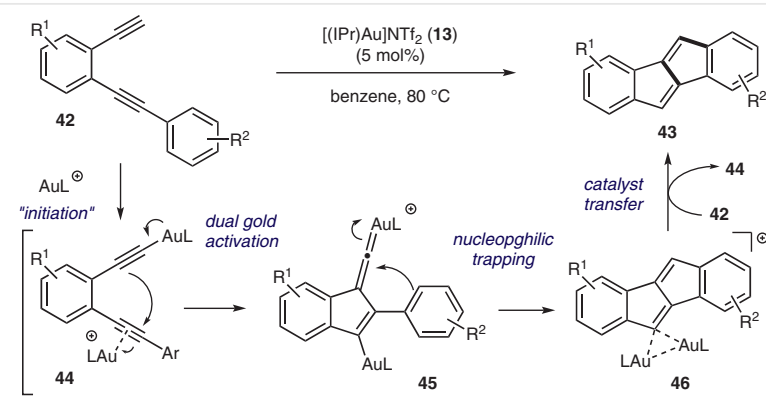

43
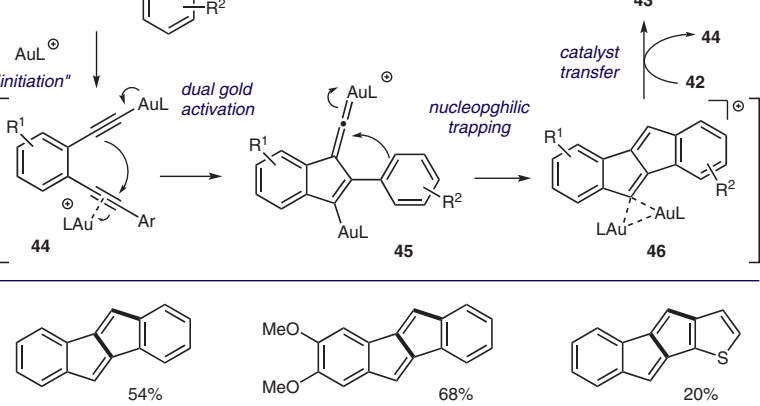

Scheme 11 Synthesis of dibenzopentalenes by dual gold catalysis

Since the gold activation of the diyne is a required step prior to the formation of the gold vinylidene species ('initiation' step), Hashmi and co-workers designed a new class of $\sigma, \pi$-acetylide digold complexes $\mathbf{4 7}$ derived from propyne, which could act as traceless dual-activation catalysts (TDACs) (Scheme 12). ${ }^{21}$ These complexes were shown particularly active in a series of transformations as exemplified by the conversion of $\mathbf{4 8}$ into dibenzopentalene $\mathbf{4 9}$ (see additional examples in the following paragraphs).

The replacement of the aryl moiety at the alkyne terminus of the substrate by a substituted allyl or benzyl group allowed an easy access to fluorenes $\mathbf{5 1}$ and benzofluorenes 52 (Scheme 13).22 The reaction should proceed in a similar manner with the initial generation of gold vinylidene $\mathbf{5 0}$, which would then suffer a nucleophilic attack of the allyl or benzyl moiety to ultimately deliver cyclized aromatic prod-
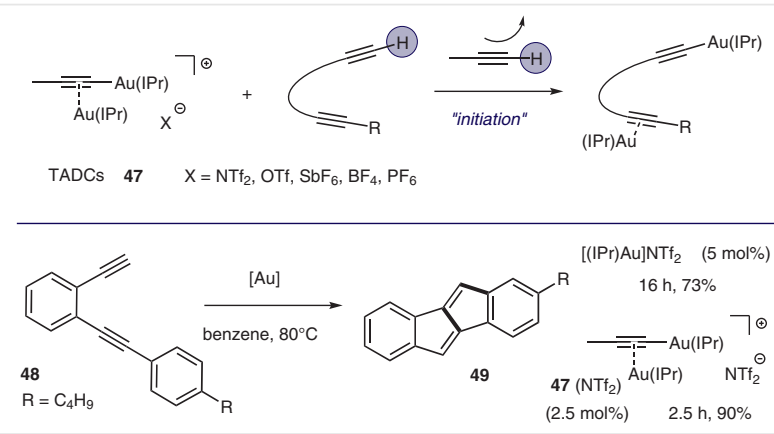

Scheme 12 б,ா-Acetylide digold complexes as traceless dual-activation catalysts

ucts. The nature of the final product depends on the substitution pattern at the allyl/benzylic position of the substrate since an additional aromatization step can take place when this position is not fully substituted.

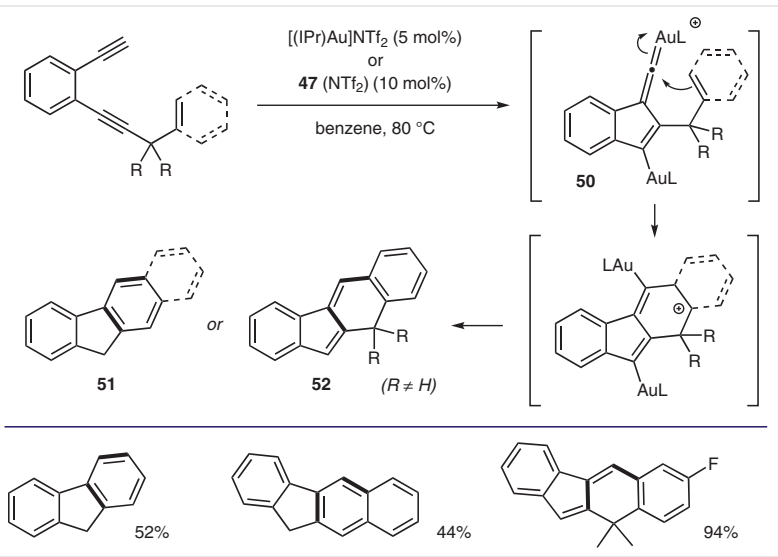

Scheme 13 Synthesis of fluorene derivatives by dual gold catalysis

Besides undergoing nucleophilic trapping with carbon $\pi$ systems, gold vinylidenes generated by dual gold catalysis can also be involved in $\mathrm{C}-\mathrm{H}$ insertion processes. This reactivity was first demonstrated independently by the groups of Zhang and Hashmi in 2012 (Scheme 14). ${ }^{23,24}$ Zhang and co-workers employed a combination of [(BrettPhos)Au] $\mathrm{NTf}_{2}$ as the catalyst and a pyridine oxide as a basic additive to convert arene diynes $\mathbf{5 3}$ into benzofulvene $\mathbf{5 7}$. While the reaction can be performed without this basic additive, its presence was shown to positively affect both the rate and the efficiency of the transformation. Hashmi and co-workers employed the catalytic system that was shown to be active in their previously reported synthesis of dibenzopentalenes. ${ }^{19}$ DFT calculations as well as D-labelling experiments support a mechanism in which a dual gold-catalyzed process allows the formation of an intermediate gold vinylidene species $\mathbf{5 5}$ that subsequently undergo a $\mathrm{C}-\mathrm{H}$ insertion. The nature of the $\mathrm{C}-\mathrm{H}$ bond activation process was studied by Hashmi, Knizia, and Klein. ${ }^{25}$ The group of Hash- 
mi was also able to isolate and characterize a gem-diaurated species $\mathbf{5 6}$ that might participate in the catalytic cycle by transferring the Au moieties to the diyne substrate 53. The transformation proved to be applicable to a large variety of substrates allowing $\mathrm{C}-\mathrm{H}$ insertion not only in primary or secondary $\mathrm{C}-\mathrm{H}$ bonds but also in $\mathrm{O}-\mathrm{H}$ and $\mathrm{N}-\mathrm{H}$ bonds.
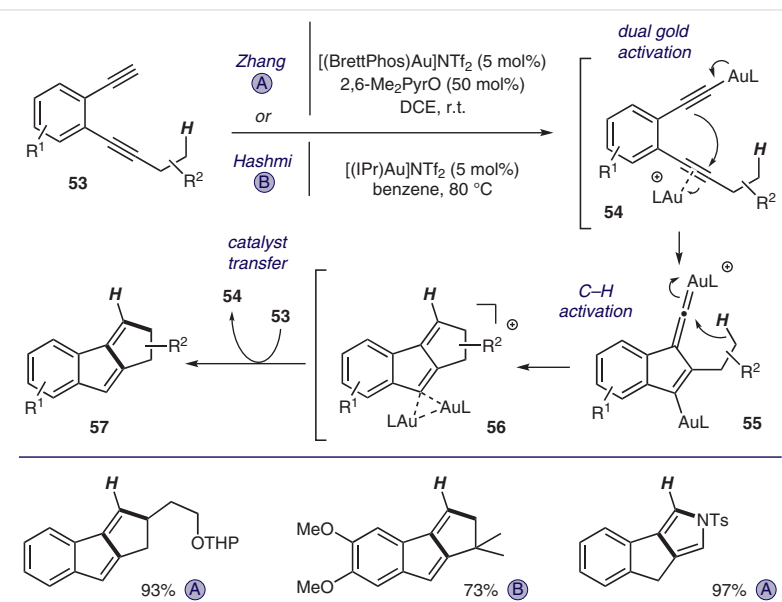

Scheme 14 Synthesis of benzofulvene derivatives by dual gold catalysis

The same $\mathrm{C}-\mathrm{H}$ bond activation process could be applied to the cycloisomerization of iodoalkyne derivatives $\mathbf{5 8}$ (Scheme 15). ${ }^{26}$ In this case, iodobenzofulvenes $\mathbf{5 9}$ were selectively obtained as the result of an iodine atom transfer from the substrate $\mathbf{5 8}$ to the gem-diaurated species $\mathbf{6 0}$. As described above, this transfer might proceed in 3 steps: $\mathrm{AuL}^{+}$transfer from $\mathbf{6 0}$ to $\mathbf{5 8}$, followed by the iodine atom transfer, and a subsequent second $\mathrm{AuL}^{+}$transfer. This transformation, which was shown to be relatively efficient, allows for further functionalization of the fulvene core by transition-metal-catalyzed cross-coupling reactions.
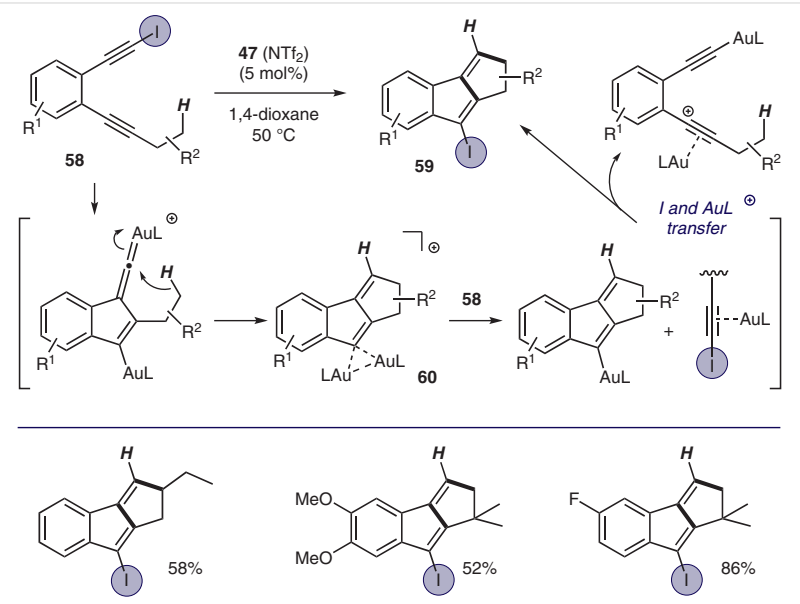

Scheme 15 Synthesis of iodobenzofulvene by iodine atom transfer
With the very same substrate $\mathbf{3 3}$ that led to the initial discovery of gold vinylidene generation by dual gold catalysis (see Scheme 10), Hashmi and co-workers demonstrated that intermolecular reactions of gold vinylidene $\mathbf{6 1}$ with alkanes or alkenes was also accessible (Scheme 16). ${ }^{27}$ Reactions of $\mathbf{6 1}$ with cycloalkanes (employed as the solvent) led to the isolation of substituted naphthalenes $\mathbf{6 2}$ in moderate yields. The mechanism for this transformation was not detailed. The reaction was more efficient when the trapping of 61 was performed in the presence of linear or cyclic alkenes. In this case, fused cyclobutene derivatives $\mathbf{6 4}$, derived from the gold-catalyzed rearrangement of the intermediate alkylidenecyclopropane $\mathbf{6 3}$ could be isolated.

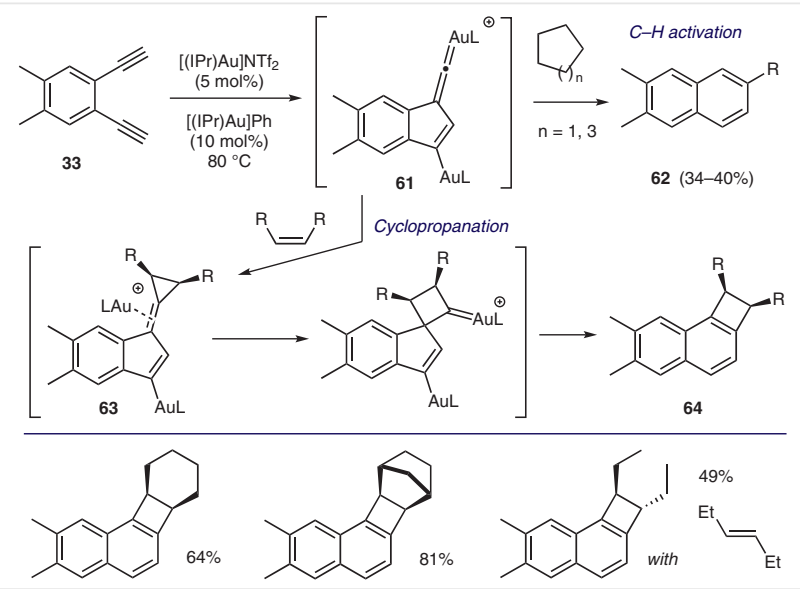

Scheme 16 Intermolecular $\mathrm{C}-\mathrm{H}$ activation and cyclopropanation with gold vinylidene species

Interestingly, while aryldiynes of type $\mathbf{6 5}$ were shown to undergo a dual gold-catalyzed 5-endo-dig cyclization leading to the formation of gold vinylidene species 66, it was demonstrated by the Zhang group that the cyclization event could alternatively proceed following a 6-endo-dig mode when the aryl group tethering the two alkyne moieties was replaced by an alkene 67 (Scheme 17). ${ }^{28}$ This shift in cyclization mode lead to the formation of intermediate orthoaurophenyl cations $\mathbf{6 8}$, which can also be regarded as carbenes 69. These species were shown to react via $\mathrm{C}-\mathrm{H}$ activation or with nucleophilic patterns to produce a variety of aromatic compounds. The same observation was made by the group of Hashmi with 2,3-dialkynylthiophene derivatives 70 (Scheme 17). ${ }^{29}$ Interestingly, the regioisomeric 3,4 dialkynylthiophenes $\mathbf{7 1}$ react similarly to aryldiynes $\mathbf{6 5}$ following 5-endo-dig cyclization process leading to gold vinylidene intermediates. ${ }^{30}$ Computational studies by Hashmi and co-workers showed that this divergence in selective arises from electronic and not steric effect.

However, the presence of an unsaturated $\mathrm{C}=\mathrm{C}$ motif between the two alkyne units is not a structural requirement to enable the dual gold-catalyzed generation and selective 
<smiles>C#Cc1ccccc1C#CCCC</smiles><smiles>N#CC1=CC=CC2=CC=CC12</smiles><smiles>C#CC(C)=CC</smiles>

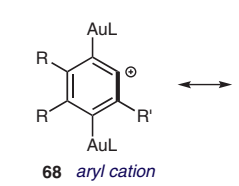

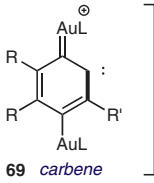<smiles></smiles>$$
\text { }
$$<smiles></smiles><smiles></smiles><smiles></smiles><smiles>CC(C)=Cc1cscc1C=N</smiles>

Scheme 17 5-endo-dig versus 6-endo-dig cyclization pathways in dual gold catalysis of 1,5-diynes

reaction of gold vinylidenes. The group of Van der Eycken has reported for instance that diynamides $\mathbf{7 2}$, which can be obtained in a straightforward manner by an Ugi reaction, could be cyclized into cyclopentapyridone derivatives $\mathbf{7 4}$ in the presence of a catalytic amount of [(IPr)Au]OTf in 1,2-dichloroethane at $120{ }^{\circ} \mathrm{C}$ (Scheme 18). ${ }^{31}$ In this transformation, the gold vinylidene species $\mathbf{7 3}$, produced intermedi-

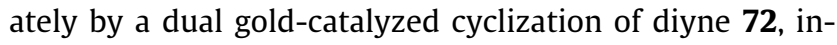
serts into a primary or tertiary inactivated $\mathrm{C}-\mathrm{H}$ bond to generate a new five-membered fused cycle.

In the same vein, Hashmi, Fuji, and Ohno demonstrated that dual gold catalysis could also be applied to the cyclo-
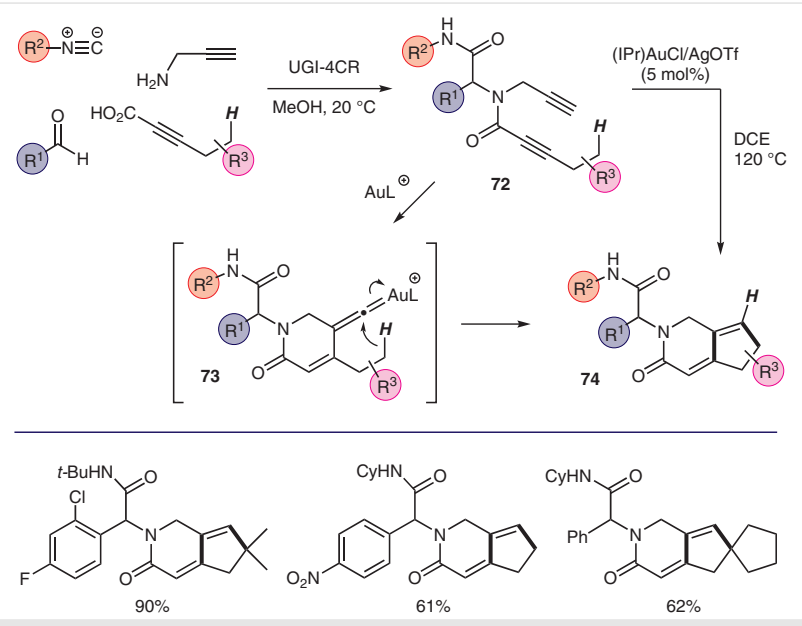

Scheme 18 C-H activation with gold vinylidenes using diyne substrates produced by an Ugi reaction isomerization of substrates $\mathbf{7 5}$ possessing a simple two carbon alkyl moiety tethering the two alkyne units (Scheme 19). ${ }^{32}$ Depending on the substitution pattern of the substrate linker, the intermediate gold vinylidene species $\mathbf{7 6}$ could evolve either via $\mathrm{C}-\mathrm{H}$ activation or nucleophilic trapping. As for the reactivity trend, competition experiments showed that 1 ) the $\mathrm{C}-\mathrm{H}$ activation pathway was more favorable than the nucleophilic trapping by an aromatic ring and 2 ) nucleophilic trapping by aromatics led preferentially to the formation of a new 6-membered (as compared to a 5membered one). In a recent article, the group of Hashmi reported another example of selective nucleophilic trapping using polyarylated 1,5 -hexadiyne substrates. ${ }^{33}$ Selected examples of such transformations are given in Scheme 19.
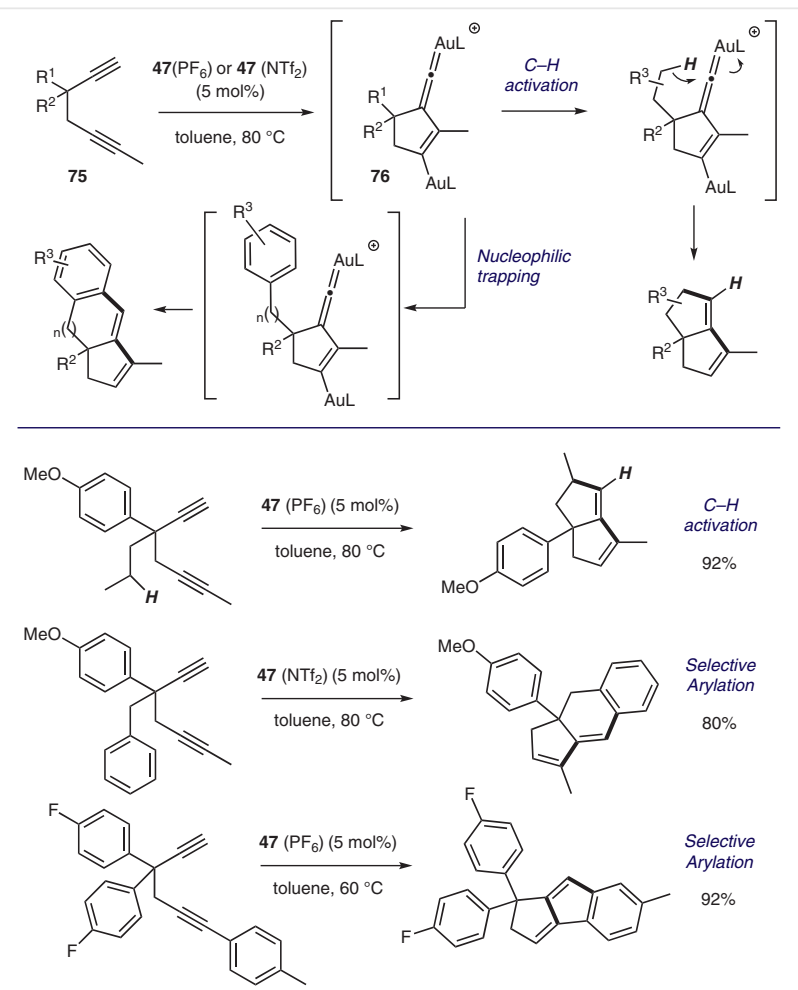

Scheme 19 Selective reactivity of gold vinylidene species generated from variously functionalized 1,5-hexadiyne substrates

Gold vinylidene generated by dual gold catalysis also proved to be useful species for the synthesis of various nitrogen containing heterocyclic motifs. For example, and by analogy with the work performed with aryldiyne substrates, the group of Hashmi developed a procedure for the synthesis of polyclic fused pyridines $\mathbf{8 0}$ from pyridinium substrates $\mathbf{7 7}$ (Scheme 20). ${ }^{34}$ Initial tests showed that the cycloisomerization could not be directly performed from the 'free' pyridines, presumably due to their capacity to strongly bind to gold catalysts. It is also interesting to note that while simple methylpyridium salts exhibit a low to moderate reactivity, the benzyl ones $\mathbf{7 7}$ bearing either a 
$\mathrm{PF}_{6}{ }^{-}$or $\mathrm{NTf}_{2}{ }^{-}$counteranion, could be readily and efficiently converted into 79 by treatment with [(IPr)Au] $\mathrm{NTf}_{2}$ at $55^{\circ} \mathrm{C}$ in dichloromethane. The transformation, which involves the $\mathrm{C}-\mathrm{H}$ insertion of gold vinylidene $\mathbf{7 8}$ as the key step, could be employed for the synthesis of a variety of polycyclic pyridinium 79. These salts could be subsequently hydrogenated and debenzylated to liberate the corresponding free pyridines $\mathbf{8 0}$. This protocol appears to be particularly useful as it allows a rapid access to structural motifs, which are found in molecules described to possess insecticidal or antimicrobial properties.

Several synthetic procedures have also been reported using ynamide derivatives as substrates for the synthesis of heterocyclic structures. Ohno, Hashmi, and Fuji have

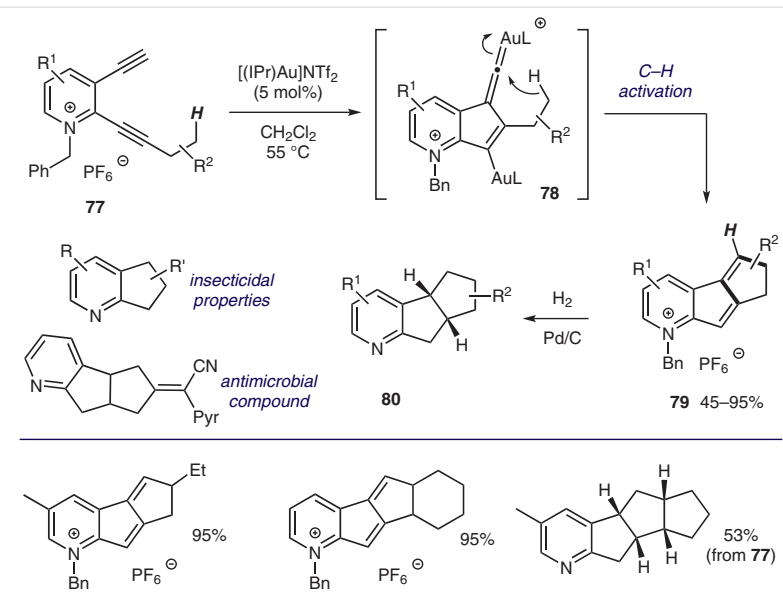

Scheme 20 Access to polycyclic pyridinium salts and pyridines by dual gold catalysis
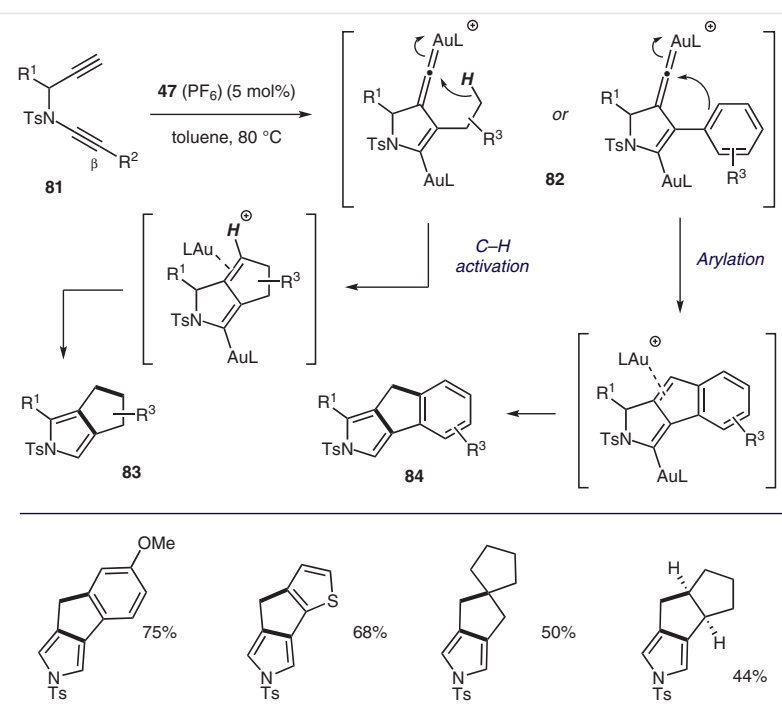

Scheme 21 Synthesis of pyrrole derivatives by $\mathrm{C}-\mathrm{H}$ activation or nucleophilic trapping of gold vinylidene species demonstrated that $N$-propargyl ynamide of type $\mathbf{8 1}$ could be converted in moderate to goods yield into 3,4-disubstituted polyclic pyrroles $\mathbf{8 3}$ and $\mathbf{8 4}$ (Scheme 21).$^{35}$ The introduction of a nitrogen atom in the diyne tether does not affect the reactivity previously observed for substrates possessing an all-carbon linker. The intermediate gold vinylidene $\mathbf{8 2}$ was found capable of performing either $\mathrm{C}-\mathrm{H}$ activation or nucleophilic trapping to produce pyrrole derivative $\mathbf{8 3}$ or $\mathbf{8 4}$, respectively. The $\mathrm{C}-\mathrm{H}$ activation turned out to be generally more efficient than the arylation process. It is worth noting that the cyclization leading to $\mathbf{8 2}$ proceeds by umpolung via the addition of the nucleophilic goldacetylide to the carbon of the ynamide.

Recently, our group reported that structurally similar ynamide substrates $\mathbf{8 5}$ possessing a longer linker between the two alkyne units could similarly react to produce a variety of N-containing aromatic heterocycles 88 (Scheme $22) .^{36}$ The use of [(RuPhos)Au]NTf ${ }_{2}$ in refluxing chloroform was found to be a set of optimal catalytic conditions to perform the transformation. The use of a pyridine additive was observed to increase the reaction rates and in some cases to significantly improve the yields. In contrast to the previously reported dual gold-catalyzed reactions that proceed by 5endo-dig cyclization, the given transformation singularly involves either a 5-, 6-, or 7-exo-dig cyclization. This process allows for the generation of a key gold vinylidene intermediate 86, which subsequently reacts in an intramolecular manner with a nucleophilic alkenyl or aryl moiety to produce a new substituted phenyl or naphthyl motif. Overall, this transformation can be regarded as an intramolecular gold-catalyzed formal dehydro-Diels-Alder reaction between an enyne and an alkyne. We also performed a series of D-labeling experiments and kinetic studies that support the involvement of a dual gold catalysis mechanism with species $\mathbf{8 6}$ and $\mathbf{8 7}$. The very same type of transformation was reported very recently by the group of $\mathrm{Zi}$ using [(IPr)Au] $\mathrm{NTf}_{2}$ in combination with DIPEA. ${ }^{37}$
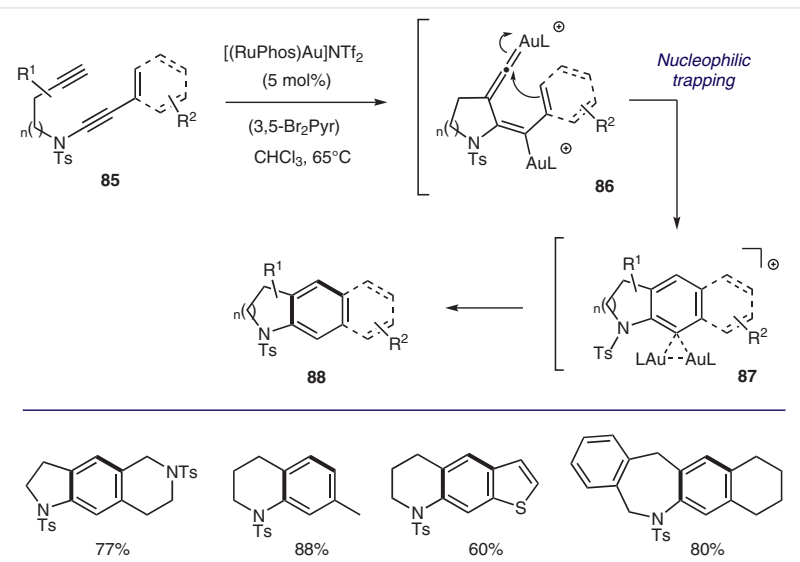

Scheme 22 Involvement of gold vinylidene species in formal dehydroDiels-Alder reactions of ynamide derivatives 
In a very recent article, Hyland and Pyne described an unusual cycloisomerization of an enediyne motif $\mathbf{8 9}$ that produces isoindolinones 94 (Scheme 23). ${ }^{38}$ The singularity of this process lies in the fact that the dual catalyzed cyclization event involves the initial addition of a nucleophilic goldacetylide on the alkene moiety of the gold-activated enyne (see $\mathbf{9 0} \rightarrow \mathbf{9 1}$ ). The resulting gold vinylidene species 91 subsequently cyclizes onto the allenylgold moiety to deliver a new gold carbene intermediate $\mathbf{9 2}$. The rearrangement of $\mathbf{9 2}$ into a six-membered cycle $\mathbf{9 3}$ followed by aromatization of the system finally produce $\mathbf{9 4}$. This mechanism was supported by a combination of D-labeling experiments and DFT calculations. An alternative direct pathway leading to 93 from $\mathbf{9 1}$ was also suggested. This transformation was found to perform best with the oxo $\left[\left(\mathrm{Ph}_{3} \mathrm{PAu}\right)_{3} \mathrm{O}\right] \mathrm{BF}_{4}$ gold complex in toluene at reflux to deliver a variety of isoindolinones 94 in high yields. Interestingly, the propiolamide substrates $\mathbf{8 9}$ could be easily obtained from the corresponding protected amino aldehydes $\mathbf{9 5}$ with high enantiopurity, and the gold-catalyzed transformation was found to retain this level of purity.
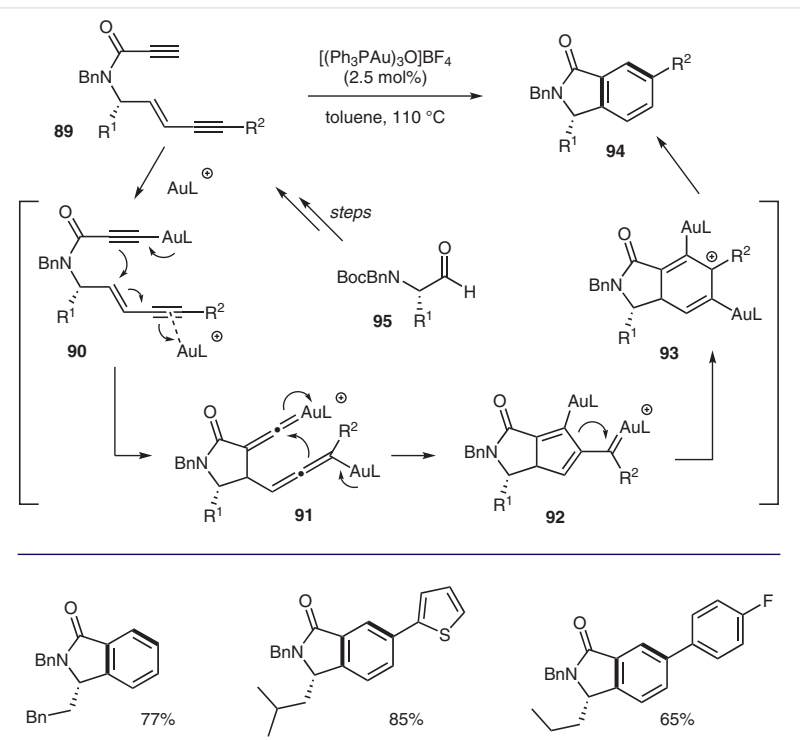

Scheme 23 Gold vinylidenes as intermediates in the synthesis of isoindolinones by dual gold catalysis

Besides performing $\mathrm{C}-\mathrm{H}$ activation or undergoing nucleophilic trapping with C-nucleophiles, gold vinylidene species have also been demonstrated to react with oxygenbased nucleophiles. As reported by the group of Hashmi, ${ }^{39} \mathrm{a}$ gold vinylidene $\mathbf{9 7}$ intermediately generated by dual gold catalysis from an aryldiyne substrate $\mathbf{9 6}$ can, for instance, react with water (Scheme 24). This nucleophilic trapping generates an aurated enol $\mathbf{9 8}$ which then tautomerizes to the gold acyl species 99. A subsequent $\mathrm{CO}$ extrusion produces the alkylgold 100, which ultimately yield the indane product 101 either by protodemetalation or by catalyst transfer with substrate $\mathbf{9 6}$. The CO loss was confirmed by GC/MS spectrometry measurements using either ${ }^{18} \mathrm{O}$-labeled water or a substrate ${ }^{13} \mathrm{C}$-labeled at the alkyne carbon being removed by $\mathrm{CO}$ extrusion. Since the trapping of the vinylidene intermediate with water proceeds in an intermolecular fashion, a specific design of the substrate is required to prevent (or limit) any competitive intramolecular $\mathrm{C}-\mathrm{H}$ activation or nucleophilic trapping. The reaction was shown to be the most efficient when it was performed with the [(IPr)Au] $\mathrm{NTf}_{2}$ as the catalyst in THF at room temperature with only 5 equivalents of water. The efficiency was, however, shown to be strongly dependent on the substrate substitution pattern.
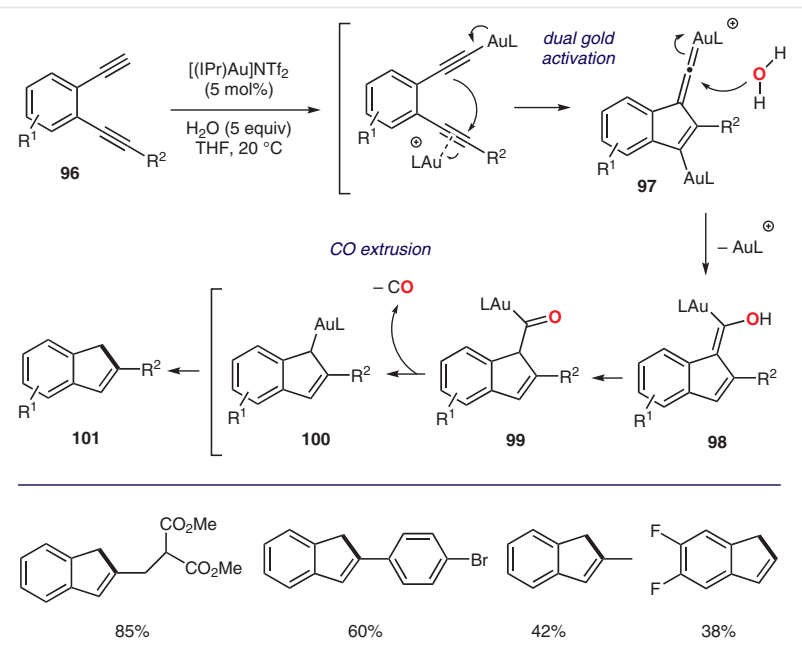

Scheme 24 Reaction of gold vinylidene species with water

Intramolecular transfers of alkoxy groups to gold vinylidene species is also feasible as reported by the Zhang group. ${ }^{40}$ When aryl diynes $\mathbf{1 0 2}$ possessing a methoxy group at the propargylic position were reacted with a catalytic amount of [(IPr)Au] $\mathrm{NTf}_{2}$ in a $t-\mathrm{BuOH} / \mathrm{DCE}$ mixture at $70{ }^{\circ} \mathrm{C}$, various polyclic fused cylopentenones 106 could be obtained (Scheme 25). To explain their formation, the authors proposed that a transfer of the methoxy group from the allylic position to the gold vinylidene moiety could proceed in the intermediately formed species 103. A subsequent isomerization of the resulting carbocation 104 would allow a Nazarov-type cyclization that would ultimately lead to the formation of $\mathbf{1 0 6}$ after hydrolysis of cyclopentadiene $\mathbf{1 0 5}$.

The same group later reported that gold vinylidene $\mathbf{1 0 8}$ derived from aryldiyne 107, could also react with 3,5-dichloropyridine oxide to generate in situ a diaurated ketene 109 (Scheme 26). ${ }^{41}$ This species could subsequently suffer an intra- or intermolecular nucleophilic attack of an alcohol or even water to produce indene derivatives $\mathbf{1 1 1}$ bearing either a lactone, an ester, or a carboxylic acid functional group. The key oxidation step of $\mathbf{1 0 8}$ into $\mathbf{1 0 9}$ with the pyridine oxide was supported by DFT calculations, as well as the involvement of the gem-digold species 110. This three- 
component reaction, which can be regarded as an oxidative cyclization of a diyne, was shown to be efficient and applicable to a large variety of substrates.

As seen from the different examples of reactions compiled in this section, dual gold catalysis represents a particularly efficient means of generating gold vinylidene species from diyne substrates. Depending on the nature of the linker between the two alkyne units and the substitution pattern of the substrate, these reactive electrophilic intermediates can undergo $\mathrm{C}-\mathrm{H}$ insertion at a non-activated position or react with carbon and oxygen nucleophiles to produce a variety of polycyclic (aromatic) compounds.
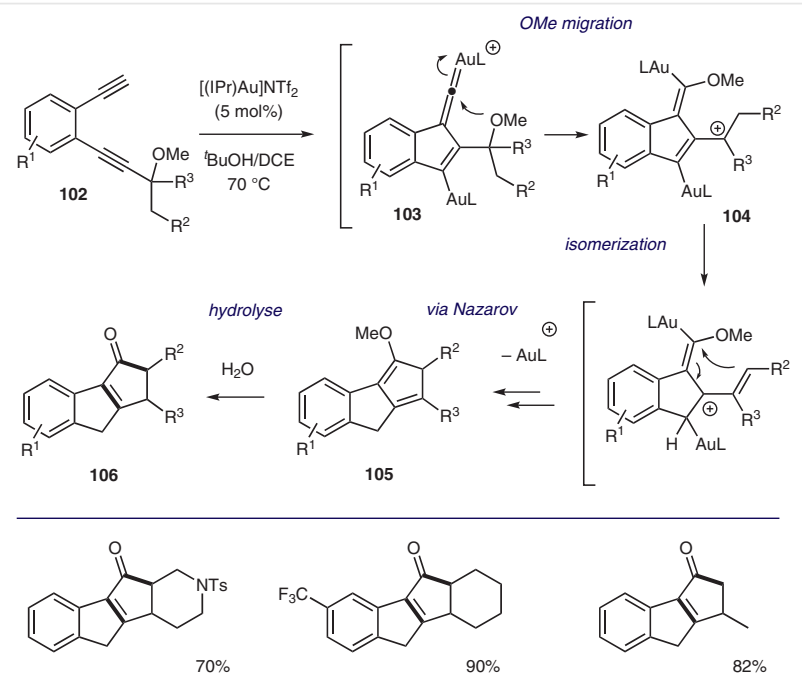

Scheme 25 Intramolecular migration of a methoxy group onto a gold vinylidene
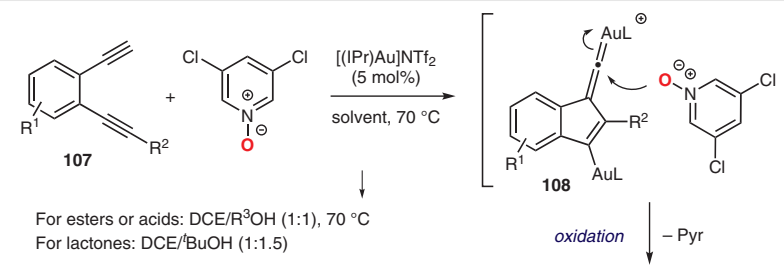
For lactones: DCE/BBOH (1:1.5
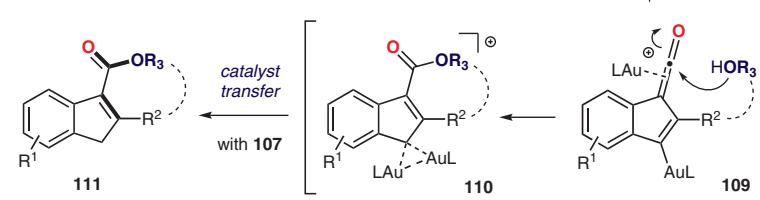

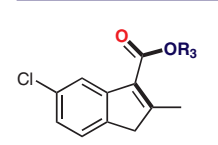

$83 \%$

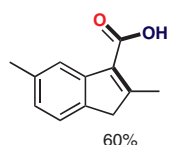

$60 \%$

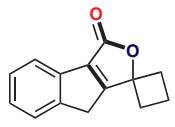

$83 \%$

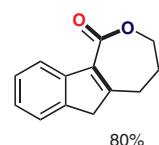

$80 \%$

Scheme 26 Oxidation of gold vinylidene species to ketene and their intra-or intermolecular trapping

\section{Other Processes}

Besides 1,2-migration of iodine or silyl groups from the terminal position of a gold-activated alkyne or dual gold catalysis of diynes, a few other processes have been reported for the generation and use of gold vinylidene intermediates. These alternative methods are described in the following paragraphs.

The group of Zhang has reported in 2016 that TMS-protected ynones 112 could be converted into 2-bromocyclopentenones $\mathbf{1 1 6}$ by treatment of $\mathbf{1 1 2}$ with a catalytic amount of (IPr)AuCl and $\mathrm{AgSbF}_{6}$ in the presence of $\mathrm{N}$-bromoacetamide (NBA) as the brominating agent (Scheme 27). ${ }^{42}$ This transformation was shown to be high yielding, compatible with various commonly used functional groups and, regio- and stereoselective. While the mechanism has not been completely elucidated, the authors have proposed on the basis of experimental studies that the reaction proceeds via the intermediate formation of a bromovinylidene species 115. The latter can then undergo a $\mathrm{C}-\mathrm{H}$ insertion at a non-activated position of a pendant alkyl group. As for the generation of 115, it was suggested that under the reaction conditions, the silylalkyne first converts into the goldacetylide 113. Upon activation of the $\mathrm{C}=\mathrm{O}$ bond in $\mathbf{1 1 3}$ by an acidic species $\left(\mathrm{Ag}^{+} / \mathrm{TMS}^{+}\right)$, a gold allenylidene species $\mathbf{1 1 4}^{43}$ would form and subsequently react with NBA to produce 115. The corresponding bromoalkyne was demonstrated not to be an intermediate in this transformation, thus ruling out the possibility of a 1,2-migration process (see Section 2). The nature of the $\mathrm{C}-\mathrm{H}$ insertion step was computationally studied by Hashmi, Knizia, and Klein. ${ }^{25}$

Hashmi and co-workers also demonstrated that goldacetylides 118, generated in situ by reaction between a terminal alkyne $\mathbf{1 1 7}$ and the gold pre-catalyst $\mathbf{1 1 9}$, could perform a nucleophilic attack at a position bearing an aryl sul-
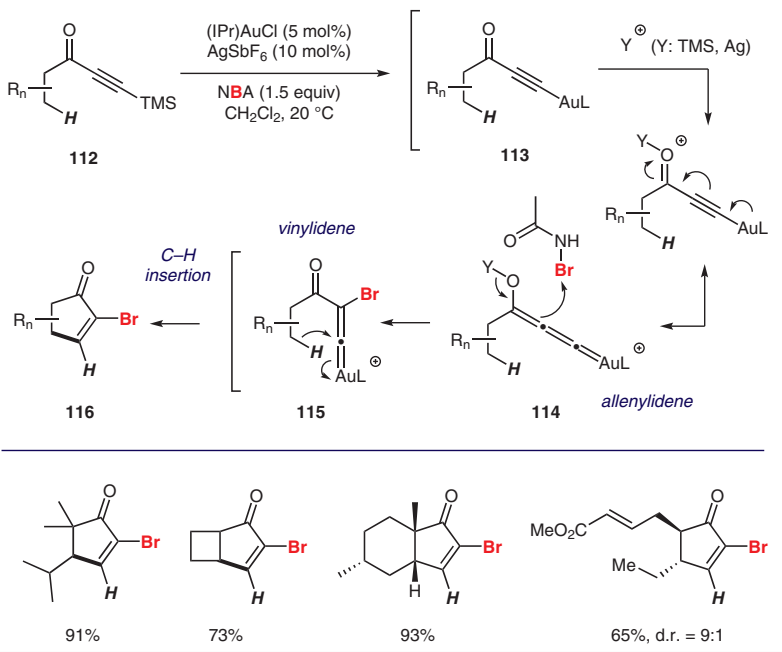

Scheme 27 Generation of gold vinylidenes from goldacetylides under acidic conditions 
fonate leaving group, thus allowing the formation of a gold vinylidene species $\mathbf{1 2 0}$ (Scheme 28 ). ${ }^{7,44}$ A subsequent attack of the sulfonate anion on $\mathbf{1 2 0}$ generates an aurated alkenyl intermediate 121, which, in turn, undergoes a catalyst transfer with the substrate to deliver the alkenyl sulfonate product 122 and regenerate the goldacetylide 118. Both, 5 and 6-membered cycles could be produced in moderate to good yields following this procedure. The efficiency of the transformation was found to be dependent on the nature and substitution pattern of the chain tethering the alkyne moiety and the sulfonate group: geometrically restricted substrates were observed to be more reactive. While the scope of this transformation remains so far limited, the easy access to the substrates and the usefulness of the alkenyl sulfonate products makes this approach particularly attractive from a synthetic point of view.

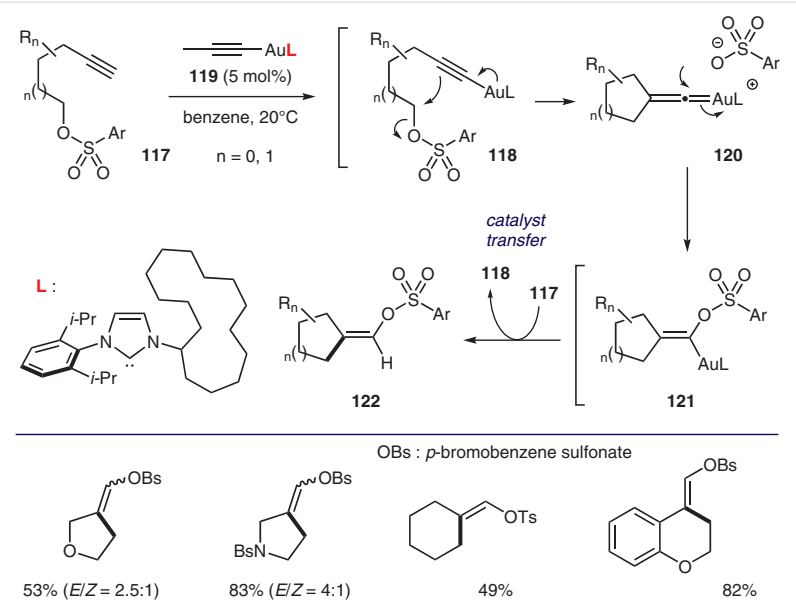

Scheme 28 Generation of gold vinylidenes by substitution of sulfonate leaving groups with a goldacetylide

Recently, Fürstner and Debrouwer reported another protocol for the generation of gold vinylidene species by an intermolecular nucleophilic attack of a goldacetylide on an activated aldehyde (Scheme 29 ). ${ }^{45}$ While this study was not dedicated to the development of a new synthetic transformation, the described procedure undoubtably possesses some synthetic potential. The authors have shown that the treatment of goldacetylide 124, generated by reaction of the TMS-alkyne $\mathbf{1 2 3}$ with a stoichiometric amount of (IPr)AuOH, with TBSOTf at $-78^{\circ} \mathrm{C}$ led to the formation of a transient gold vinylidene species $\mathbf{1 2 5}{ }^{46}$ This process probably involves the nucleophilic addition of the goldacetylide moiety onto an $\mathrm{O}$-silyloxocarbenium intermediate. Interestingly, 125 rapidly evolved at $-78^{\circ} \mathrm{C}$ via the formal transfer of the oxygen residue from the benzylic position to the carbenic one to produce the HOTf-acylgold complex 126. At $20^{\circ} \mathrm{C}, \mathbf{1 2 6}$ suffered an extrusion of CO that produced 127 . Alternatively, its treatment with methanol delivered the corresponding ester 128. Both intermediates 125 and 126 could be detected using NMR spectrometry technics and the structure of $\mathbf{1 2 6}$ was confirmed by X-ray analysis.

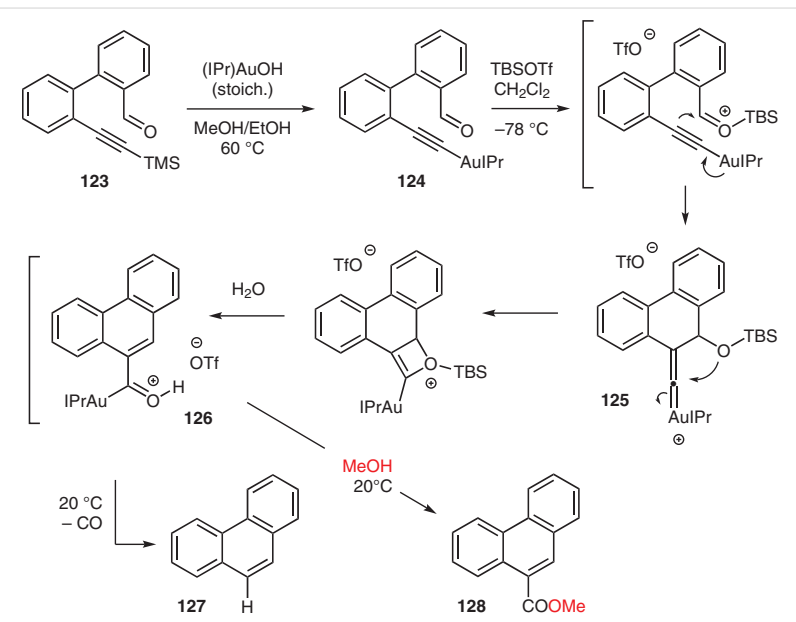

Scheme 29 Transient vinylidene species generated by reaction between a goldacetylide and an oxocarbenium ion

Finally, Fensterbank, Gandon, and Gimbert have reported the involvement of intermediate gold vinylidene species 132 in the gold-catalyzed selective conversion of 1,6-allenynes 129 into hydrindienes 133 (Scheme 30). ${ }^{47}$ The singularity of the process, as compared to those presented above, lies in the mechanism leading to the formation of the gold vinylidene. The authors have proposed based on a series of D-labeling experiments and computational studies, that the alkenylgold species $\mathbf{1 3 1}$, initially produced by nucleophilic attack of the allene in $\mathbf{1 3 0}$ on the gold-activated alkyne moiety, could undergo a favorable 1,4-hydride shift. This unusual transfer would produce a gold vinylidene in-
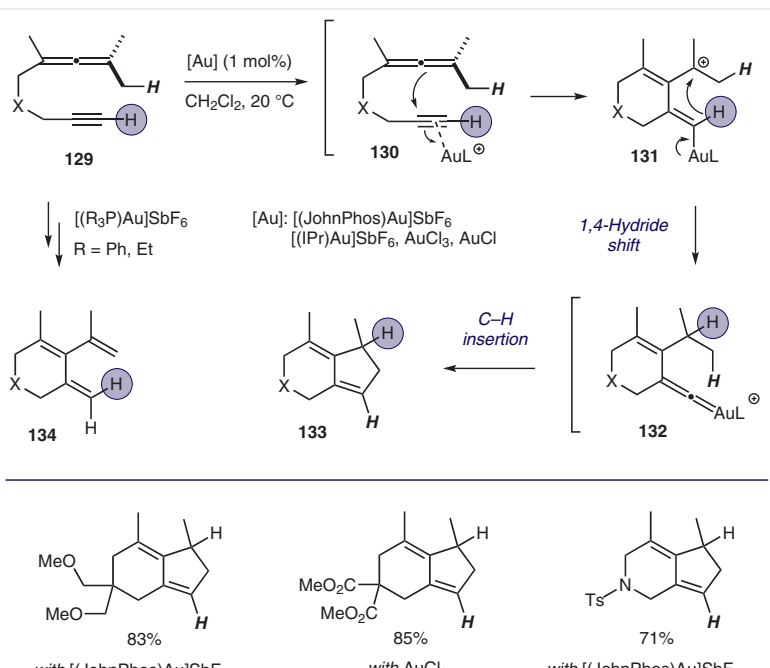

with [(JohnPhos)Au]SbF。

with $\mathrm{AuCl}_{3}$

with $[(\mathrm{JohnPhos}) \mathrm{Au}] \mathrm{SbF}_{6}$

Scheme 30 Generation of gold vinylidenes by hydride transfer from an intermediate alkenyl-gold species 
termediate $\mathbf{1 3 2}$ which, in turn, could insert into a non-activated $\mathrm{C}-\mathrm{H}$ bond to deliver compound 133. Interestingly, while this process was found to be very efficient with gold complexes bearing bulky phosphine or NHC ligands [as well as gold(I)/(III) halides], the use of gold(I) complexes possessing less sterically demanding ligands $\left(\mathrm{Et}_{3} \mathrm{P}, \mathrm{Ph}_{3} \mathrm{P}\right)$ led to a divergence in selectivity with the formation of Alder-ene type products 134 .

\section{Conclusion}

While gold vinylidenes species have been proposed as reactive intermediates in synthetic processes as early as 2004, the development of transformations based on their efficient generation and selective reaction has only started in 2012, after the groups of Hashmi and Zhang uncovered the synthetic potential of dual gold catalysis with diyne substrates. Although gold vinylidenes can be accessed by a 1,2-migration process from Au-activated halogeno- or silylalkynes (see Section 2), this route lacks generality. Depending on the reaction conditions and the substitution pattern of the substrate, the 1,2-migration pathway can be in competition with the direct nucleophilic functionalization of the alkyne and/or with the dehalogenation/desilylation of the gold-activated alkyne. In contrast, and as exemplified in Section 3, the use of dual gold catalysis with diyne substrates has been shown to be a far more robust and reliable way to produce gold vinylidenes. The reactivity principle lies in the possibility to generate in situ, from a terminal alkyne, a goldacetylide that would undergo an intramolecular nucleophilic addition onto a second gold-activated alkyne. The increased number of studies that have been made in the field of dual gold catalysis during the last 5 years have already allowed enlightening some unique and unsuspected reactivities of gold vinylidenes. These species have been demonstrated to react, for instance, with carbon or oxygen-based nucleophiles, by oxidation or by $\mathrm{C}-\mathrm{H}$ insertion at a non-activated center. If one considers that the regioselective reaction of an electrophilic species at the carbon of a goldacetylide could theoretically generate a gold vinylidene species, the application of this simplistic reactivity principle with various electrophiles should lead in the future to new exciting discoveries and consequently to an increasing interest for the use of gold vinylidenes in synthetic organic chemistry.

\section{Acknowledgment}

The University of Ottawa and the Natural Sciences and Engineering Research Council are acknowledged for financial support, and Prof. P. Knochel for the kind invitation to contribute to this special issue.

\section{References}

(1) For selected reviews on homogeneous gold catalysis, see: (a) Hashmi, A. S. K.; Hutchings, G. J. Angew. Chem. Int. Ed. 2006, 45, 7896. (b) Hashmi, A. S. K. Chem. Rev. 2007, 107, 3180. (c) Fürstner, A.; Davies, P. W. Angew. Chem. Int. Ed. 2007, 46, 3410. (d) Jiménez-Núñez, E.; Echavarren, A. M. Chem. Commun. 2007, 333. (e) Li, Z.; Brouwer, C.; He, C. Chem. Rev. 2008, 108, 3239. (f) Arcadi, A. Chem. Rev. 2008, 108, 3266. (g) Gorin, D. J.; Sherry, B. D.; Toste, F. D. Chem. Rev. 2008, 108, 3351. (h) Patil, N. T.; Yamamoto, Y. Chem. Rev. 2008, 108, 3395. (i) Dorel, R.; Echavarren, A. M. Chem. Rev. 2015, 115, 9028. (j) Qian, D.; Zhang, J. Chem. Soc. Rev. 2015, 44, 677. (k) Joost, M.; Amgoune, A.; Bourissou, D. Angew. Chem. Int. Ed. 2015, 54, 15022. (l) Pflästerer, D.; Hashmi, A. S. K. Chem. Soc. Rev. 2016, 45, 1331. (m) Zheng, Z.; Wang, Z.; Wang, Y.; Zhang, L. Chem. Soc. Rev. 2016, 45, 4448. (n) Day, D. P.; Chan, P. W. H. Adv. Synth. Catal. 2016, 358, 1368.

(2) For a review on gold carbenes and other cationic intermediates relevant to gold catalysis, see: Harris, R. J.; Widenhoefer, R. A. Chem. Soc. Rev. 2016, 45, 4533.

(3) Hashmi, A. S. K. In Molecular Catalysts: Structure and Functional Design; Gade, L. H.; Hofmann, P., Ed.; Wiley-VCH: Weinheim, 2014, 89.

(4) Mamane, V.; Hannen, P.; Fürstner, A. Chem. Eur. J. 2004, 10, 4556.

(5) Soriano, E.; Marco-Contelles, J. Organometallics 2006, 25, 4542.

(6) Morán-Poladura, P.; Suárez-Pantiga, S.; Piedrafita, M.; Rubio, E.; González, J. M. J. Organomet. Chem. 2011, 696, 12.

For a study on the parameters affecting the stability of vinylidene gold species, see:

(7) Nunes dos Santos Comprido, L.; Klein, J. E. M. N.; Knizia, G.; Kästner, J.; Hashmi, A. S. K. Chem. Eur. J. 2016, 22, 2892.

(8) Morán-Poladura, P.; Rubio, E.; González, J. M. Beilstein J. Org. Chem. 2013, 9, 2120.

(9) Morán-Poladura, P.; Rubio, E.; González, J. M. Angew. Chem. Int. Ed. 2015, 54, 3052.

(10) Nösel, P.; Müller, V.; Mader, S.; Moghimi, S.; Rudolph, M.; Braun, I.; Rominger, F.; Hashmi, A. S. K. Adv. Synth. Catal. 2015, 357, 500.

(11) Seregin, I. V.; Gevorgyan, V. J. Am. Chem. Soc. 2006, 128, 12050.

(12) Xia, Y.; Dudnik, A. S.; Li, Y.; Gevorgyan, V. Org. Lett. 2010, 12, 5538.

(13) McGee, P.; Bellavance, G.; Korobkov, I.; Tarasewicz, A.; Barriault, L. Chem. Eur. J. 2015, 21, 9662.

(14) Bellavance, G.; Barriault, L. Angew. Chem. Int. Ed. 2014, 53, 6701.

(15) Hashmi, A. S. K.; Braun, I.; Rudolph, M.; Rominger, F. Organometallics 2012, 31, 644.

(16) For reviews and highlight on dual gold catalysis, see: (a) Hashmi, A. S. K. Acc. Chem. Res. 2014, 47, 864. (b) Braun, I.; Mohamed Asiri, A.; Hashmi, A. S. K. ACS Catal. 2013, 3, 1902. (c) Gómez-Suárez, A.; Nolan, S. P. Angew. Chem. Int. Ed. 2012, 51, 8156. For seminal examples of dual gold-catalyzed processes, see: (d) Cheong, P. H.-Y.; Morganelli, P.; Luzung, M. R.; Houk, K. N.; Toste, F. D. J. Am. Chem. Soc. 2008, 130, 4517. (e) Odabachian, Y.; Le Goff, X. F.; Gagosz, F. Chem. Eur. J. 2009, 15, 8966.

(17) For a study by the same group on aryl cation generation under gold catalysis, see: Wurm, T.; Bucher, J.; Rudolph, M.; Rominger, F.; Hashmi, A. S. K. Adv. Synth. Catal. 2017, 359, 1637. 
(18) For a mass spectrometry study aimed at detecting intermediates in this transformation, see: Greisch, J.-F.; Weis, P.; Brendle, K.; Kappes, M. M.; Haler, J. R. N.; Far, J.; De Pauw, E.; Albers, C.; Bay, S.; Wurm, T.; Rudolph, M.; Schulmeister, J.; Hashmi, A. S. K. Organometallics 2018, 37, 1493.

(19) Hashmi, A. S. K.; Wieteck, M.; Braun, I.; Nösel, P.; Jongbloed, L.; Rudolph, M.; Rominger, F. Adv. Synth. Catal. 2012, 354, 555.

(20) (a) Højer Vilhelmsen, M.; Hashmi, A. S. K. Chem. Eur. J. 2014, 20 , 1901. (b) Højer Larsen, M.; Houk, K. N.; Hashmi, A. S. K. J. Am. Chem. Soc. 2015, 137, 10668. (c) Villegas-Escobar, N.; Højer Larsen, M.; Gutiérrez-Oliva, S.; Hashmi, A. S. K.; Toro-Labbé, A. Chem. Eur. J. 2017, 23, 13360.

(21) Hashmi, A. S. K.; Lauterbach, T.; Nösel, P.; Højer Vilhelmsen, M.; Rudolph, M.; Rominger, F. Chem. Eur. J. 2013, 19, 1058.

(22) Bucher, J.; Wurm, T.; Taschinski, S.; Sachs, E.; Ascough, D.; Rudolph, M.; Rominger, F.; Hashmi, A. S. K. Adv. Synth. Catal. 2017, 359, 225.

(23) Ye, L.; Wang, Y.; Aue, D. H.; Zhang, L. J. Am. Chem. Soc. 2012, 134, 31.

(24) Hashmi, A. S. K.; Braun, I.; Nösel, P.; Schädlich, J.; Wieteck, M.; Rudolph, M.; Rominger, F. Angew. Chem. Int. Ed. 2012, 51, 4456.

(25) Klein, J. E. M. N.; Knizia, G.; Nunes dos Santos Comprido, L.; Kästner, J.; Hashmi, A. S. K. Chem. Eur. J. 2017, 23, 16097.

(26) Nösel, P.; Lauterbach, T.; Rudolph, M.; Rominger, F.; Hashmi, A. S. K. Chem. Eur. J. 2013, 19, 8634.

(27) Hashmi, A. S. K.; Wieteck, M.; Braun, I.; Rudolph, M.; Rominger, F. Angew. Chem. Int. Ed. 2012, 51, 10633.

(28) Wang, Y.; Yepremyan, A.; Ghorai, S.; Todd, R.; Aue, D. H.; Zhang, L. Angew. Chem. Int. Ed. 2013, 52, 7795.

(29) (a) Hansmann, M. M.; Rudolph, M.; Rominger, F.; Hashmi, A. S. K. Angew. Chem. Int. Ed. 2013, 52, 2593. (b) Tšupova, S.; Hansmann, M. M.; Rudolph, M.; Rominger, F.; Hashmi, A. S. K. Chem. Eur. J. 2016, 22, 16286. (c) Tšupova, S.; Rudolph, M.; Rominger, F.; Hashmi, A. S. K. Chem. Eur. J. 2017, 23, 12259.

(30) Hansmann, M. M.; Tšupova, S.; Rudolph, M.; Rominger, F.; Hashmi, A. S. K. Chem. Eur. J. 2014, 20, 2215.

(31) Vachhani, D. D.; Galli, M.; Jacobs, J.; Van Meervelt, L.; Van der Eycken, E. V. Chem. Commun. 2013, 49, 7171.

(32) Wieteck, M.; Tokimizu, Y.; Rudolph, M.; Rominger, F.; Ohno, H.; Fujii, N.; Hashmi, A. S. K. Chem. Eur. J. 2014, 20, 16331.
(33) Plajer, A. J.; Ahrens, L.; Wieteck, M.; Lustosa, D. M.; Babaahmadi, R.; Yates, B.; Ariafard, A.; Rudolph, M.; Rominger, F.; Hashmi, A. S. K. Chem. Eur. J. 2018, 24, 10766.

(34) Tšupova, S.; Cadu, A.; Stuck, F.; Rominger, F.; Rudolph, M.; Samec, J. S. M.; Hashmi, A. S. K. ChemCatChem 2017, 9, 1915.

(35) Tokimizu, Y.; Wieteck, M.; Rudolph, M.; Oishi, S.; Fujii, N.; Hashmi, A. S. K.; Ohno, H. Org. Lett. 2015, 17, 604.

(36) Zhao, Q.; León Rayo, D. F.; Campeau, D.; Daenen, M.; Gagosz, F. Angew. Chem. Int. Ed. 2018, 57, 13603.

(37) Wang H.-F., Wang S.-Y., Qin T.-Z., Zi W.; Chem. Eur.J.; 2018, 24: in press; DOI 10.1002/chem.201804529

(38) Hyland C., Zamani F., Babaahmadi R., Gardiner M. G., Ariafard A., Pyne S. G., Yates B.; Angew. Chem. Int. Ed.; 2018, 57: in press; DOI 10.1002/anie.201810794

(39) (a) Bucher, J.; Stößer, T.; Rudolph, M.; Rominger, F.; Hashmi, A. S. K. Angew. Chem. Int. Ed. 2015, 54, 1666. (b) Raubenheimer, H. G. ChemCatChem 2015, 7, 1261.

(40) Yu, C.; Chen, B.; Zhou, T.; Tian, Q.; Zhang, G. Angew. Chem. Int. Ed. 2015, 54, 10903.

(41) Yu, C.; Ma, X.; Chen, B.; Tang, B.; Paton, R. S.; Zhang, G. Eur.J. Org. Chem. 2017, 1561.

(42) Wang, Y.; Zarca, M.; Gong, L.-Z;; Zhang, L. J. Am. Chem. Soc. 2016, $138,7516$.

(43) For gold allenylidene species, see: (a) Kim, N.; Widenhoefer, R. A. Angew. Chem. Int. Ed. 2018, 57, 4722. (b) Hansmann, M. M.; Rominger, F.; Hashmi, A. S. K. Chem. Sci. 2013, 4, 1552. (c) Xiao, X.-S.; Kwong, W.-L.; Guan, X.; Yang, C.; Lu, W.; Che, C.-M. Chem. Eur. J. 2013, 19, 9457. (d) Jin, L.; Melaimi, M.; Kostenko, A.; Karni, M.; Apeloig, Y.; Moore, C. E.; Rheingold, A. L.; Bertrand, G. Chem. Sci. 2016, 7, 150.

(44) Bucher, J.; Wurm, T.; Swamy Nalivela, K.; Rudolph, M.; Rominger, F.; Hashmi, A. S. K. Angew. Chem. Int. Ed. 2014, 53, 3854.

(45) Debrouwer, W.; Fürstner, A. Chem. Eur. J. 2017, 23, 4271.

(46) For another study on the synthesis and characterization of a gold vinylidene complex, see: Harris, R. J.; Widenhoefer, R. A. Angew. Chem. Int. Ed. 2015, 54, 6867.

(47) Jaroschik, F.; Simonneau, A.; Lemière, G.; Cariou, K.; Agenet, N.; Amouri, H.; Aubert, C.; Goddard, J.-P.; Lesage, D.; Malacria, M.; Gimbert, Y.; Gandon, V.; Fensterbank, L. ACS Catal. 2016, 6, 5146. 